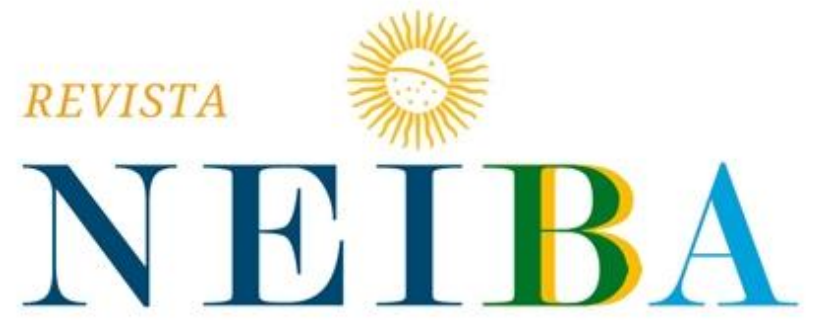

CADERNOS ARGENTINA-BRASIL
Volume 9, 2020, p. 01-18

DOI: 10.12957/neiba.2020.50771 I e50771 I ISSN: 2317-3459

\title{
MALVINAS: NO LAS QUERAMOS TANTO
}

\section{AS AMAMOS TANTO ASSIM? A QUESTÃO MALVINAS NA POLÍTICA EXTERIOR ARGENTINA}

\section{Vicente Palermo ${ }^{1}$}

${ }^{1}$ Club Político Argentino (CONICET), Buenos Aires, Buenos Aires, Argentina. E-mail: vicentepalermo@gmail.com ORCID: https://orcid.org/0000-0002-9039-1847

Recebido em: 04/05/2020. 


\section{RESUMEN}

El artículo tiene una doble función. Por un lado, informativo: pone en conocimiento del lector aspectos poco entendidos, aunque relevantes, de la cuestión de Malvinas/Falklands con respecto a la política exterior argentina en el contexto del marco jurídico-político internacional. Por otro lado, desarrolla una discusión más política y propositiva que académica, basada en el análisis del desarrollo de la política exterior hasta hoy, proponiendo cambios sustanciales en esta materia.

Palabras-clave: Malvinas; Falklans; Política exterior Argentina.

\section{RESUMO}

O artigo cumpre uma função dupla. Por um lado, informativa: põe em conhecimento do leitor aspectos pouco compreendidos, embora relevantes, da questão Malvinas/Falklands no que diz respeito à política externa argentina no contexto do arcabouço jurídico-político internacional. Por outro, desenvolve uma discussão mais política e propositiva que acadêmica, nos alicerces da análise do desenrolar da política externa até nossos dias, propondo mudanças substanciais nesta matéria.

Palavras-chaves: Malvinas; Falklans; Política exterior Argentina. 
En este artículo no me propongo exponer o defender mis opiniones sobre qué hay que hacer en la cuestión Malvinas (Palermo, 2007), tanto como informar a muchos lectores - probablemente una inmensa mayoría de ellos - sobre la naturaleza de algunos problemas políticos y jurídicos muy mal conocidos. La razón de este esfuerzo es que ese desconocimiento, que abarca a la inmensa mayoría de la opinión pública, es en sí mismo un componente de la cuestión Malvinas, dado que facilita determinadas acciones contraproducentes y dificulta otras positivas.

Como se sabe, la política oficial para Malvinas, y para un numeroso contingente de intelectuales y publicistas de desigual calidad, consiste en la recuperación de la soberanía sobre las islas, tal como lo fija la Constitución Nacional vigente. En arreglo a estos fines, que denomino aquí convencionales, las tres estrategias históricamente palpables son: el reclamo para forzar la negociación, el arbitraje y el uso de la fuerza. Cada una es peor que la otra, son inconducentes cuando no autodestructivas. Separamos una cuarta estrategia, la negociación bilateral en sí misma, porque es cualitativamente diferente y, más allá de la cartilla oficial, es abierta: admite una gama de objetivos más variada. Del uso de la fuerza, afortunadamente, ni hablar, pero ya lo probamos (y lo festejamos) en 1982 y desde entonces queremos obcecadamente desconocer las consecuencias de ese paso en falso, con el pretexto de que fue encarado por una dictadura militar.

Quedan por tanto tres caminos al alcance de los gobiernos, el arbitraje, el reclamo para forzar la negociación, y la negociación bilateral per se (metodológicamente, creo que es pertinente separar reclamo de negociación bilateral por las razones que espero queden claras a lo largo del texto). El meollo de este artículo es el que sigue: ¿por qué el gobierno descarta el arbitraje e insiste en el reclamo? ¿Es, el reclamo, un buen camino para lograr una negociación bilateral? Y ¿cuál es el juego que delimita los alcances de la negociación bilateral?

Veamos primero la opción por el arbitraje. No me molesta que este examen parta de un umbral de total ingenuidad. ¿Por qué la Argentina no ha decidido, jamás que yo sepa, incoar el contencioso en la Corte de La Haya? Me parece que la pregunta es ingenua pero lógica. Si puede hacerlo por sí sola, ¿por qué no lo hace? De hecho, no 
faltan los especialistas que desde hace unos años vienen sosteniendo que "hay que ir a La Haya". Si no recuerdo mal, un artículo de uno de ellos en Clarín está titulado: "No queda alternativa: hay que ir a La Haya". Entonces, ¿por qué no se va a La Haya? ¿Cancillería no confía suficientemente en la fortaleza jurídica de la posición argentina? ¿Hay otros motivos? ¿Por qué insisten en ir, quienes insisten?

Se puede responder que, en parte, Argentina no va a La Haya porque no puede. Un miembro de la ONU puede estar interesado en dirimir sus diferencias con otro a través de dos caminos: un procedimiento contencioso y un procedimiento consultivo. En el primero la Corte falla, emite sentencia, y su fallo es (en teoría al menos) vinculante; en el segundo se solicita del tribunal que emita un dictamen: que dé su opinión experta y conforme a derecho internacional sobre el tema del caso (aunque no es vinculante tiene un pesado valor). Bueno, si se examinan con cuidado el Estatuto y el Reglamento de la Corte Internacional de Justicia, surge claramente que la Corte es una ciudadela bien rodeada de murallas. Ningún estado miembro de la ONU puede abrir con su sola voluntad un caso contencioso. No puede "ir a La Haya” por su exclusiva decisión, eso no existe. Asimismo ningún estado miembro puede abrir un procedimiento consultivo. Esto es clarísimo. Solamente organismos colectivos de la UN (la Asamblea General, el Consejo de Seguridad, y organismos especializados autorizados por la AG) pueden abrir una solicitud de opinión consultiva en la Corte. Si lo hacen, la Corte está obligada a estimarla (como mínimo, a examinar si se considera o no competente). En lo que se refiere a contenciosos, la jurisdicción de la Corte alcanza, como dijimos, a cuestiones en las que las dos partes han sometido al tribunal su disputa. Es cierto que el Estatuto (cap. III, Procedimiento, art. 53) dice "1. Cuando una de las partes no comparezca ante la Corte, o se abstenga de defender su caso, la otra parte podrá pedir a la Corte que decida a su favor.". Pero esto supone la constitución previa de dos estados miembros, en partes. Así, no hay ningún impedimento para que un estado, por su propia cuenta, incoe, y se constituya en demandante; pero para que se constituyan dos estados miembros en partes demandada y demandante, se requiere el consentimiento de ambos estados. Sólo una vez que ambos estados estén constituidos como partes, tiene aplicación el art. 53 del Reglamento. En ese caso, sí, la parte demandada no está 
obligada a comparecer o defender su caso, pero prácticamente da por seguro que pierde, si no comparece. El procedimiento continúa y a solicitud de la parte demandante el fallo puede ser en contra de la demandada.

El Reglamento - Sección C, Procedimiento ante la Corte, Incoación del procedimiento, Artículo 38, 5, confirma, a mi juicio, esta interpretación, porque dice: "Cuando el demandante pretenda fundar competencia de la Corte en un consentimiento todavía no dado o manifestado por el Estado contra quien se haga la solicitud, ésta última se transmitirá a ese Estado. No será, sin embargo, inscrita en el Registro General ni se efectuará ningún acto de procedimiento hasta tanto el Estado contra quien se haga la solicitud no haya aceptado la competencia de la Corte a los efectos del asunto de que se trate.".

De cualquier modo debe quedar claro que si los estados se constituyen como partes, los jueces de la Corte pueden desestimar el caso, declararse incompetentes, etc. Si no es así, el contencioso arribará a un fallo. Parece indiscutible que este camino está cerrado para la Argentina. Cualquier presentación argentina para llevar el caso Malvinas a un contencioso en la CIJ será simplemente desestimada por Gran Bretaña, con sus argumentos habituales si falta hiciere decir algo: a. que sus títulos de soberanía sobre las islas son incuestionables; b. que el estado argentino desató una guerra de agresión contraria al derecho internacional y la perdió y c. que los isleños no quieren saber nada con la Argentina. En suma, el procedimiento contencioso está cerrado.

Sin embargo, exploremos el otro camino, porque una historia muy diferente es la de los procedimientos consultivos. En materia consultiva, se plantea a mi juicio una paradoja, porque si bien, ya lo dijimos, ningún estado miembro puede incoar en la Corte una solicitud de procedimiento consultivo, sí puede hacerlo un colectivo que, si está de acuerdo, puede llevar, por su vez, el pedido de consulta ante la Corte. He ahí el caso: un estado miembro plantea a un colectivo que lleve una consulta ante la Corte, y i ieste colectivo tiene que decidir si hacerlo o no!! Políticamente es patente que se constituye de este modo un caso, en el seno de ese colectivo: la pugna por una decisión a favor o en contra de llevar el pedido a la Corte. Quien gana, gana mucho, aunque el procedimiento culmine en la emisión de un dictamen, opinión consultiva por parte de la 
CIJ, que no será vinculante en relación a los objetivos finales de los estados involucrados. Es patente que políticamente el proceso - con una o dos instancias (en el colectivo y en el tribunal) - tendría gran valor.

Pues bien, el establishment malvinero doméstico repite hasta el cansancio el mantra sobre el respaldo de la Asamblea General de las Naciones Unidas a la posición argentina. Es muy difícil estar expuesto a los medios de comunicación y no haber escuchado mil veces el tópico del respaldo internacional a los derechos argentinos. ¿Por qué, entonces, la Argentina no acude a la Asamblea General solicitando que esta inicie un procedimiento consultivo ante la Corte Internacional de Justicia? A mi juicio, la respuesta es sencilla, Argentina tiene dos motivos: primero, no concurre a la Asamblea porque teme no reunir allí el número de estados miembros necesario para efectuar la solicitud ante la Corte. Si no alcanza ese número, la Resolución Aurea (2065) quedaría seriamente dañada. Y segundo, no lo hace en la clave de esa gastada sentencia, "ten cuidado con tus deseos, no sea cosa que se vuelvan realidad". Porque, en otras palabras, teme fundadamente las consecuencias de su éxito en lograr convencer a la Asamblea que lleve un pedido de acción consultiva a la Corte. Hay demasiada incertidumbre y Argentina, aunque no lo dice, sabe que por este camino puede desbaratar su único activo, que es la Resolución 2065 de la Asamblea General (año 1965). ¿Por qué este riesgo? Es archisabido que la Asamblea General, votando a favor 94 estados, ninguno en contra, con 14 abstenciones y 9 ausentes, reconoció en 1965 que Malvinas se encuadra en una situación colonial en la que, a fin de encontrar una solución pacífica del problema, las partes, que son dos (Gran Bretaña y Argentina) deben resolver sin demora una disputa de soberanía y que para esto deben tomarse en cuenta los intereses de los habitantes de las islas. Nótese que el próximo diciembre se cumplirán 55 años de esta resolución. Nótese asimismo que tras la incorporación de Sudán del Sur, en 2011, el número de estados miembros ascendió a 193 (creció casi un 100\%). En 55 años las cosas han cambiado bastante, y esto es políticamente significativo. Por ejemplo: el peso de la Argentina en la escena internacional es ahora mucho menor, debido a nuestra pérdida de gravitación relativa.

La narrativa oficial insiste - también es archiconocido - en que la 2065 hizo del 
diferendo Malvinas un caso especial. Y es cierto. ¿Por qué? Porque insertó el diferendo en el proceso de descolonización, al mismo tiempo en que no habló de los deseos de los malvinenses sino de sus intereses. Sus intereses, y no necesariamente sus deseos, son los que según la resolución deben tomarse en cuenta. De este modo, y ya claramente en el terreno de las interpretaciones, no en el de la letra, la cuestión de la descolonización habría cobrado un cariz básicamente territorial: habría dos partes, la colonizadora - Gran Bretaña - y la que fue víctima de la colonización - Argentina. Hay una gente que vive en las islas, sí, pero no son un pueblo, no cuentan sus deseos y apenas cuentan sus intereses - entendidos estos por las dos - y sólo dos - partes que negocian: Gran Bretaña y la Argentina. Es un caso especial porque está encuadrado, en suma, en la descolonización pero no en la autodeterminación del pueblo que habita el territorio. Ningún argentino más o menos informado ignora esto.

Pero, más allá de que esta forma de entender el problema hace agua por donde se la mire, lo importante aquí es que las cosas han mutado dramáticamente en las últimas décadas, en las que es cada vez más difícil sostener - delante del sentido común jurídico político y las pautas culturales internacionales - que los malvinenses no constituyen un actor colectivo cuyos deseos deban ser considerados, sino que simplemente sus intereses deben ser interpretados por las partes en conflicto y definidos en la negociación, al modo, pongamos por ejemplo, en que el Congreso de Viena definió fronteras tras las guerras napoleónicas o el Tratado de Versalles lo hizo una vez finalizada la Primera Guerra Mundial. No se trata - vuelvo al principio - de lo que yo piense al respecto. Eso aquí no tiene mucha importancia. Se trata de cómo y cuánto han cambiado las cosas, la correlación de fuerzas entre pautas culturales, jurídicas, internacionales, que mutan, y los estados. Para empezar hay que admitir que los británicos tenían un punto, y en él se hicieron fuertes: argumentaron que sí, que los intereses son los que cuentan, pero si hay dos partes en la negociación, una de ellas está en perfecto derecho de sostener (tanto como la otra lo contrario, pero más aún por el hecho de que la ONU reconoce a Gran Bretaña como potencia administradora) que si está a su cargo respetar los intereses de los isleños, pues un modo razonable de respetarlos es preguntarles: pero, ustedes, ¿qué desean? Pero la cosa fue, y sigue 
yendo, mucho más allá: en una Asamblea General numéricamente ampliada por naciones y estados que son más sensibles al principio de autodeterminación - y lo son menos al principio de descolonización, en gran medida porque ahora queda sobre el planeta una descolonización residual -, el activismo isleño, la argumentación británica, y, last but not least, la memoria de la agresión militar argentina de 1982 (que se cargó a los isleños), hace que la posición argentina resulte muchísimo menos simpática que en 1965. Pruebas al canto: muy recientemente, en febrero pasado, el Secretario General de la ONU, António Guterres, hizo unas sugestivas declaraciones. Refiriéndose a los territorios en descolonización remanentes (17 entre ellos Malvinas) dijo que "la gente en esos territorios está todavía esperando que la promesa del autogobierno resulte honrada". No parece que estuviera distraído Guterres al señalar que "la descolonización es un proceso que debe ser guiado por las aspiraciones y necesidades de las comunidades que viven en los territorios". Esto es clarísimo, y en las palabras del Secretario General no se hace ninguna referencia a Malvinas como caso especial. "Es nuestro deber - insiste Guterres, metiendo todo en la misma bolsa - atender a las preocupaciones y amplificar la voz de quienes viven en esos territorios". Está muy claro para qué lado sopla el viento. Como observa Andrés Cisneros - con quien discrepo con el mayor respeto en otros puntos de su análisis - la posición de Guterres implícitamente saca a la Argentina del juego, que queda reducido a un diálogo entre la potencia administradora y los habitantes.

En suma, está cada vez más difícil hablar de la cuestión y preservar a Malvinas, conforme al punto de vista argentino, como un caso de descolonización especial. Así, imaginemos las dificultades del estado que, por convicción o conveniencia, cargue con la tarea de abogar por la hipotética aspiración argentina - que la AG solicite a la CIJ un dictamen consultivo - ante los miembros de la Asamblea. Supongamos que Sudán del Sur sea invitado a acompañar la posición argentina. Quizás el representante de ese país no conozca en profundidad la cuestión Malvinas, pero en todo caso seguramente averiguará. Y una de las primeras cosas que averiguará es que los habitantes de las islas aborrecen a los argentinos, no a los argentinos genéricamente considerados, faltaba más, pero sí a aquellos que sostienen que los deseos de los isleños no tienen arte ni 
parte. ¿Acompañar qué? - se preguntará el representante de Sudán del Sur. Sí, es verdad, está aquella resolución de hace 55 años - pensará -, pero, ¿̇acaso hay alguna forma menos imperfecta de respetar los intereses de los isleños que preguntarles a ellos mismos qué es lo que quieren? Mejor, que los argentinos esperen. En suma, el horno no está para bollos: si la Argentina tomara la iniciativa de propugnar la formulación de un pedido de la Asamblea General a la ClJ de un pronunciamiento consultivo, es extremadamente probable que el resultado sea una derrota diplomática y por tanto política. Cancillería no lo ignora, pero no lo dice. Este es el problema. La geografía política de la AG ha cambiado en 55 años, las tendencias contemporáneas vinculan más y más fuertemente la soberanía estatal a la gente que a la tierra. Pero no hay por qué hacerlo público. En Malvinas, nuestra política oficial es esotérica. Los filósofos malvineros hablan bajito porque si levantan la voz la ciudad se podría traumatizar. Mejor seguir evocando la 2065 como recién salidita del horno. Que el lector saque sus conclusiones.

Pero, supongamos que me equivoco, y que Argentina consigue reunir una mayoría de miembros de la AG a favor de solicitar un dictamen de la CIJ sobre la cuestión de fondo, la soberanía sobre el archipiélago. Bueno, si el lector cree que de ahí en adelante todo será pan comido está - a mi criterio - completamente equivocado. Un juzgamiento por parte de un tribunal internacional no se parece en nada con una cuentita. Ni dos más dos son cuatro ni tres por cinco quince. En el fallo de una corte internacional intervienen multitud de imponderables y variables y consideraciones de lo más diversas. Esto no equivale a otra cosa que a la incertidumbre. El estado que invoca el juicio de la Corte se expone a un proceso cuyo resultado no puede dar en absoluto por descontado; es un juego que se parecerá más a arrojar los dados al aire que al ajedrez. Pero séame permitido apurar el cáliz amargo; no faltarán lectores que estimen que, a pesar de todo, Argentina puede confiar en que sus títulos sobre las islas son tan sólidos que difícilmente haya jueces que se nieguen a reconocer la soberanía. Pues lamento decirles que también en esto están equivocados. La creencia en que los derechos argentinos sobre Malvinas son incontrovertibles ya no es más que un prejuicio forjado por los aparatos educativos y culturales a lo largo de los años y arraigado 
profundamente en el sentido común, a fuerza de constante y huera reiteración complaciente, aunque viene siendo contestada desde hace algunos años. No estoy queriendo decir que en arreglo al derecho internacional la Argentina no tenga algunos puntos a su favor, o que los derechos que el estado británico se atribuye a sí mismo tal como lo hace el estado argentino - sean los que no admiten discusión. Es al revés: tanto Argentina como Gran Bretaña tienen títulos de derecho muy precariamente establecidos sobre las islas. El activismo jurídico británico no es inferior al argentino, y confrontando los argumentos en torno a las distintas cuestiones, es raro que se pueda arribar a resultados concluyentes. Cuestiones que son, para el compendio argentino de la ortodoxia malvinera, artículos de fe, como el uti possidetis iures, la ocupación efectiva, o la continuidad del reclamo contra el estado usurpador, no disfrutan en absoluto de fundamentos, pruebas y títulos irrebatibles. Las argumentaciones británicas sobre estos y prácticamente todos los puntos que sostienen el reclamo de soberanía, son especulares (véase Potts, 2019, para muestra basta un botón). Examinadas con atención, se puede percibir que estamos tan flojitos de papeles como los ingleses. Nos guste o no, afirmar que tenemos razón es un acto puramente político (sin despreciar) y no podemos estar seguros de que algún tribunal nos dé esa razón, del mismo modo que los ingleses tampoco pueden.

Otra vez, dos más dos no será cuatro, porque los activos argumentales y documentales que aporten las partes estarán sujetos básicamente a una tarea de interpretación, apreciación, ponderación, estimación, a cargo de los jueces. Es en la cancha que se ven los pingos, no en los mapas que colgamos en las paredes. Una vez más entramos así en el reino de la incertidumbre. La prudencia de estado - no la mía, yo no tengo nada que ver - indica que seguir un camino de suerte y verdad podría ser catastrófico - para los fines oficiales establecidos (que no comparto).

Es necesario tomar en cuenta que el arbitrio judicial - los grados de libertad de los que disponen los jueces o un tribunal para interpretar la ley - es, en el derecho internacional, enorme. Por ejemplo, según la normativa de La Haya, si bien se estipula que la función del tribunal es "decidir conforme al derecho internacional las controversias que le sean sometidas", se indica que el cuerpo deberá aplicar no 
solamente "las convenciones internacionales, sean generales o particulares, que establecen reglas expresamente reconocidas por los Estados litigantes", sino también "la costumbre internacional como prueba de una práctica generalmente aceptada como derecho". Mientras que las reglas expresamente reconocidas son una materia bastante precisa, la costumbre internacional y las prácticas generalmente aceptadas son un campo mucho más borroso, en el que el tribunal puede interpretar, o no, haciéndose cargo de las tendencias y las corrientes de opinión internacional que prefiera.

Abundando en razones, parecería ser que, tal como interpreto bajo mi responsabilidad el análisis del problema por parte de un diplomático muy calificado (Petrella, 2008, 2013) y que no se caracteriza precisamente por su obcecación, la resolución 2065, de factura en la Asamblea General de las Naciones Unidas, sería paradójicamente la que ha creado incentivos para mantenernos apartados de la ONU en la búsqueda de una solución. La línea asentada en Cancillería desde los tiempos de Zavala Ortiz, Ruda, Ortiz de Rozas, De la Guardia, es que recurrir a La Haya en cualquiera de sus instancias presentaría muchos más riesgos que ventajas. Ir a la Corte supondría congelar en malos términos la relación con el Reino Unido durante el proceso y probablemente también después - dada la imposibilidad de un "triunfo" y la elevada improbabilidad de un resultado satisfactorio para el territorialismo malvinero. Las represalias diplomáticas y políticas no serían insignificantes. Y la negociación bilateral conforme a las pautas particulares del caso, nos anticipamos un poco, sería lo más recomendable. Dicho de un modo más descarnado y esquemático: en la negociación bilateral está la política, en el arbitraje está el derecho. Nuestra posición ¿es sólida? No lo suficientemente como para colgar nuestros sombreros en las antesalas de un tribunal internacional. Proceder de este modo sería incurrir en la típica fuga por el derecho merecidamente criticada por estudiosos de los usos y costumbres argentinos en relaciones internacionales.

Esto nos conduce a uno de los caminos alternativos al arbitraje, el reclamo enderezado a forzar la negociación bilateral. Mientras los británicos y los isleños se sientan cómodamente sobre el diferendo y dejan que el tiempo pase - y debo reconocer que me parece una táctica inteligente - el gobierno argentino dice creer que 
por vía del ensanchamiento y de la profundización del reclamo forzará a los británicos a negociar. En esto está acompañado por publicistas y especialistas de altísimo nivel. A veces la densidad de la causa Malvinas parece obnubilarlos de tal modo que pierden, a mi juicio, un principio de realidad. Por ejemplo, argumentan (reiterada y recientemente) que el diferendo de soberanía afecta y perjudica a las islas y a los isleños, y que solucionado este los malvinenses dejarían de pagar una hipoteca tan pesada. Pero esta es una percepción adecuada para los 60 y los 70 del siglo pasado, que olvida cómo y cuánto han prosperado las islas desde la posguerra hasta nuestros días. Ensanchar - consiguiendo más respaldos mundo afuera - y profundizar - formalizando y haciendo más expreso el respaldo hacia adentro (un ejemplo es la declaración de Ushuaia de 2012) - el reclamo puede ser una gimnasia diplomática o política divertida, pero no capto la conexión que podría llevar desde ese punto hasta un convencimiento británico de negociar desconociendo los deseos de los isleños. Hemos sobreactuado seguramente sin darnos cuenta en muchos casos - como cuando aprobamos la cláusula constitucional transitoria en 1994, y la utilidad de eso es cero y el perjuicio un número desconocido pero superior a cero.

En resumidas cuentas, es todo esto - y no que los ingleses sean malos o piratas, los malvinenses unos kelpers (me da gusto comprobar que el término kelper no está en RAE y sí lo está malvinense) y los funcionarios argentinos unos inútiles - lo que explica la reproducción sine die del statu quo. Uso de la fuerza, arbitraje y reclamo son caminos bloqueados. A los británicos les conviene tirar la pelota a la tribuna cada vez que les llega a los pies, a los isleños tirársela a los británicos, y a los argentinos hacer barullo para que parezca que están llevando adelante arduamente la ofensiva por la recuperación de las islas - y los tres tienen recursos para ello: ingleses e isleños para sacar la pelota de la cancha (simplemente, ignorar el reclamo argentino por negociar) y argentinos para hacer barullo. El resultado - no podría ser otro - es la inmovilidad. Se reproduce el statu quo y mientras generaciones y generaciones de argentinos son formadas en la adoración de la causa, generaciones y generaciones de altos funcionarios públicos son formadas como expertos malvineros, que nos explican cómo la verdad está con nosotros y el mundo también, en declaraciones con buena onda pero 
perfectamente inútiles.

No obstante todo lo dicho, entender que hay tres y sólo tres caminos, y que los tres están bloqueados, es demasiado simplificador. Resulta necesario, ahora, iluminar aspectos en parte conocidos, pero también mal tratados por el publicismo malvinero que, a mi entender, politiza mal un problema que es esencialmente político. La negociación bilateral sería siempre, en teoría, el mejor instrumento para ir alcanzando gradualmente soluciones razonables para todos los interesados. Mientras que el reclamo es inconducente, o más bien contraproducente, la negociación bilateral directa sería virtualmente posible y prometedora. Digo virtualmente porque, como cae de su peso, una negociación requiere del consentimiento de al menos dos partes. Aquello que tienen en común la guerra y el reclamo (del modo en que lo hemos definido aquí) es la fuerza. La fuerza es concebida como instrumento para disponer a la otra parte a la negociación; en el caso del reclamo, se sueña con la acumulación de fuerza diplomática - valor del respaldo internacional y del aislamiento del otro. Vimos que este camino no conduce a nada. La negociación directa tiene otras promesas; me suena, paradójicamente, a la aproximación indirecta (la célebre estrategia militar y política teorizada por Liddel Hart), y es indudable que el estado argentino intentó practicarla con pericia varias veces desde 1965 hasta 2019. Así, una negociación “de fondo" tendría etapas previas. Diálogos en búsqueda de intereses comunes sin mencionar la disputa territorial; conversaciones en las que se puede mentar la disputa, pero sin comprometer los intereses comunes previamente identificados; discusiones que abordan el tema de fondo oficiosamente, de modo tal que al no suponer compromisos es posible ensayar muchas alternativas por fuera de la ortodoxia de cada país. No caben dudas de que estos términos definen, con mayor o menor precisión o alcance, tramos importantes de la relación diplomática bilateral con Gran Bretaña antes del funesto 1982, durante la década de los 90 y durante el gobierno de Cambiemos (2015-2019). Pero es significativo que los logros sobre el terreno como acuerdos sobre seguridad, hidrocarburos, pesca, comunicaciones con espíritu condominial", hayan sido siempre escasos o hayan quedado apenas en el papel y que, por tanto, a la etapa de "negociación que obliga y compromete" (Kohen, 2016), no se haya llegado nunca. Y no 
estoy, para nada, formulando una crítica; todo lo contrario. Sólo digo que en juegos de doble nivel, en los que la política exterior y la política doméstica están fuertemente articuladas, más difícil es jugar con éxito - es decir, extraer fuerza de un nivel para emplearla con provecho en el otro, desde el plano doméstico al internacional y viceversa -, cuanto mayor es la distancia entre los objetivos y predisposiciones de los actores que no se relacionan directamente entre sí - en este caso, la comunidad doméstica argentina, en especial la minoría de preferencias intensas constituida por el lobby malvinero, por un lado, y la comunidad británica y los malvinenses, por otro. En esas ocasiones, no se puede decir que la diplomacia argentina haya funcionado mal, y no faltan indicios de que espacios tácitos de virtual coincidencia entre algunos sectores de parte y contraparte (o sea, algo muy resbaladizo y relativo) se crearon. Pero los polos reactivos, extremos, de ambas partes, gravitaron de modo tal de bloquear los avances aun antes de que se alcanzara el punto crítico de bifurcación de los caminos. En otras palabras, dado que la irritación y la ira, la verborragia y el denuncismo de los polos extremos, acompañaron cualquier aproximación, nunca se llegó al punto de path dependence, a partir del cual ya se convierte en definitivamente imposible el camino alternativo, sea este el de la "recuperación" de soberanía de la Argentina, sea el del desistimiento definitivo por parte de esta. Los británicos aprendieron: entre el propósito motorizado por Ridley en 1979 - una solución a lo Hong Kong (condominio, retroarriendo, etc.) para Malvinas - y las insinuaciones de funcionarios británicos en Puerto Stanley/Puerto Argentino avanzados los 90 -, David Heacoth-Emory, alto cuadro del Foreign Office, en viaje a las islas comentó a los malvinenses que una negociación sobre soberanía era posible pero nunca por la fuerza -, media una distancia muy considerable (además de la guerra). Si miramos el lado argentino, ni hablar: recurrentemente, las mejores iniciativas de los 60, los 90 y los 2015-2019 fueron tronchadas, rápidamente revertidas al sabor de la política doméstica, ni bien el lobby malvinero tuvo la oportunidad de hacerlo. Lo que quiero decir es que la alternativa de la negociación bilateral (abandonando el amuchamiento y el apriete del reclamo) es, sin dudas, la mejor opción; pero para que prospere, los objetivos, los fines, del estado argentino en la cuestión Malvinas deberían ser sustancialmente reformulados. A mi 
juicio el nudo de este asunto estriba en ofrecer - cosa que no se hace de un gobierno a otro, mediante una simple declaración ni ninguna de esas sobreactuaciones - garantías confiables a los malvinenses de que su voluntad será respetada. Esta es una cuestión sobre todo política más que jurídica; no creo que interese tanto un reconocimiento formal del derecho a la autodeterminación como la generación de confianza en nuestras intenciones. Algo, obviamente, dados los antecedentes, muy difícil de alcanzar. Pero algún día hay que empezar. El oportunismo - explotar con la intención de obtener réditos domésticos fáciles la denuncia al "entreguismo" - estará siempre al acecho; controlarlo será una tarea permanente.

Todos los Gobiernos ponen a Malvinas "al tope de la agenda exterior de la república", como se dice oficialmente como si fuera una virtud, y a mi entender es muy malo. Y nos lleva a hacer macanas, como maltratar a Uruguay - donde los isleños quieren hacer negocios -, o a hacer afirmaciones altisonantes como la de que "toda cooperación científica o logística en materia de conservación de recursos pesqueros sin que se reanuden, con seriedad y sin dilaciones, las negociaciones en torno a la controversia de soberanía y sin que nuestro país obtenga una contraprestación sustantiva a cambio, acabará necesariamente contribuyendo al fortalecimiento de la presencia del Reino Unido en los territorios que ilegalmente ocupa" (Abruza, 2020). La causa nos lleva a embarrarnos la cancha a nosotros mismos. Autores serios, entretanto, se devanan los sesos tratando de diseñar una estrategia potencialmente exitosa en la cuestión de las islas. Disculpe el lector que sea tan asertivo: a mi juicio, esa estrategia potencialmente exitosa ni existe ni podría ser formulada, porque los objetivos de la política oficial en la materia son quiméricos. Precisamos interesar a británicos y malvinenses en una negociación bilateral, pero para esto nuestros objetivos deben ser sustancialmente reformulados. Si una política de estado hace al "bienestar material y cultural" de la nación, o del pueblo, como afirma razonablemente Juan Tokatlian, entonces los fines convencionales - los que el estado argentino viene alentando antes y después de la guerra, como si nada hubiera cambiado - y sus estrategias mal podrían definirse como política de estado, porque son contrarias al bienestar material y cultural. 
Comprar una riña con Uruguay por el nombre de un stand empresarial, o no hacer un esfuerzo serio por controlar la explotación de recursos en la región porque los británicos no se sientan a negociar, son sinsentidos. No dudo de la sinceridad de muchos malvineros y de sus buenas intenciones. Pero también tengo que decir que algunos otros, metafóricamente hablando, viven del conflicto. $Y$ necesitan mantener muchos supuestos equivocados, uno de ellos es que la causa Malvinas tiene un incontrastable arraigo popular. Esto no es cierto; cualquier argentino cree que las Malvinas son argentinas (así como los restantes archipiélagos del Atlántico Sur y la Península Antártica) porque no ha habido liderazgo político que enfrente el problema. Y el núcleo del problema es reconocer las cosas "como son" (me tiembla el pulso si lo digo sin comillas) y sustituir objetivos inalcanzables y autodestructivos por objetivos que nos permitan liberar energías y trabajar en serio por el bienestar material y cultural. Sacar Malvinas del tope nuestra política exterior, volver a fórmulas bien ideadas como la del paraguas de soberanía, reconocer la voluntad de los isleños como interlocutores genuinos, son piezas que forman, a mi juicio, parte de un abanico necesario de redefiniciones que podría ser gradualmente negociado hasta que los objetivos tradicionales puedan ser sustituidos. No voy a macanear diciendo que por ese camino vamos a "recuperar la soberanía", pero sí creo que vamos a contribuir al "bienestar material y cultural del pueblo". El camino convencional no solamente es fantasioso en lo que se refiere a recuperación, sino tóxico culturalmente y costoso materialmente. Argentina debería ser consciente de que tiene poco tiempo y recursos muy escasos, en lugar de despilfarrarlos en cosas irrelevantes. Para escándalo de muchos malvineros, diré que no somos tan pocos los que pensamos que la principal baza de negociación argentina es precisamente el reclamo de soberanía. El valor de una desistencia mesurada podría ser grande y contribuir al logro de objetivos que hacen auténticamente al bienestar material y cultural del pueblo. En la región del Atlántico Sur, la conjunción de desarrollo y cuidado medioambiental requiere en efecto de cooperación; la integración cooperativa y amigable con los isleños, por "pocos" que estos sean, tiene para nosotros un valor cultural potencial muy superior al de la geografía política (hace a nuestra hasta hoy inacabada maduración de una comunidad 
política republicana); un entendimiento con los británicos podría facilitar que la vida productiva y cultural argentina se proyectara fuera del área. La fórmula "a mayor bienestar socioeconómico, mejores probabilidades de recuperar pacíficamente las islas", que puede leerse en los mejores autores dedicados o asomados al tema, a mi juicio es un producto de la desesperación conceptual. Quiere decir muy poco, o nada. Es al revés: pacifiquemos en serio la cuestión Malvinas sustituyendo los objetivos tradicionales y liberaremos energía y espacio para un mayor bienestar socioeconómico. El sábado se hizo para el hombre, y no el hombre para el sábado. No podemos desconocer que hoy por hoy, construir un posicionamiento promisorio de Argentina en el mundo, también requiere una dosis de conflicto. Como observa - por ejemplo - el economista Osvaldo Rosales, "las redes 5 G son la clave de las tecnologías disruptivas de este siglo como inteligencia artificial, internet de las cosas, big data, e-cloud. Y para países como los nuestros es fundamental acceder rápidamente a esas redes". Ese camino, que supone ganar bienestar y competitividad, no se podrá recorrer sin un forcejeo serio con Estados Unidos. "Precisamos - continúa Rosales - ampliar nuestra espalda con mayor cooperación regional, para poder dialogar y negociar tanto con China como con Estados Unidos". Si en lugar de destinar nuestros escasos recursos materiales y humanos a esas tareas complejas, los destinamos a alcanzar un objetivo territorial del siglo XIX, no creo que nos estemos ganando la gratitud de las generaciones del futuro. 


\section{REFERENCIAS}

Abruza, A. (2020). 'La problemática jurídica y política de la cuestión Malvinas'. In Daniel Filmus (comp.), Malvinas, una causa regional justa. Buenos Aires: CLACSO, pp. 37-74.

Cisneros, A. (2020). Malvinas: Una llamativa afirmación en la ONU. Disponible en: https://www.clarin.com/opinion/malvinas-Ilamativa-afirmacion-onu_0_8Mt9EFkB.html [Consultado en: marzo de 2020].

Kohen, M. (2016). Las Malvinas tuvieron su martes 13. Disponible en: https://www.clarin.com/opinion/malvinas-martes-13_0_rJH6A19h.html [Consultado en: marzo de 2020].

Palermo, V. (2007). Sal en las heridas: Las Malvinas en la cultura argentina contemporánea. Buenos Aires: Sudamericana.

Petrella, F. (2008). 'Malvinas, Georgias y Sandwich del Sur, Diplomacia Argentina en la Naciones Unidas 1991/1999, Estudio Preliminar'. In CARI, Colección Malvinas, Georgias y Sandwich del Sur. Buenos Aires.

(2013). Malvinas: leer la realidad. Disponible en: https://opinion.infobae.com/fernando-petrella/2013/02/17/malvinas-leer-larealidad/index.html [Consultado en: marzo de 2020]

Potts, S. (2019). Falkland Islands - What the International Courts of Justice Might Say About Argentina's Claims. Disponible en: https://www.academia.edu/11204594/Falklands_-

_What_the_ICJ_Might_Say_About_Argentinas_Claims

Rosales, O. (2020). 'La economía china sube la temperatura', Revista Ñ, Clarín, 859 [Online]. Disponible en: https://www.pressreader.com/argentina/revistan/20200314/281754156391011 [Consultado en: marzo de 2020]

Tokatlian, J. G. (2020). 'Malvinas: consenso, calma y creatividad'. In Daniel Filmus (comp.), Malvinas, una causa regional justa. Buenos Aires: CLACSO, pp. 75-88. 